\title{
Management of Amyand's hernia in children: should appendectomy be mandatory or not?
}

\author{
Hisham A. Almetaher ${ }^{*}$, Mohammed A. Mansour and Mohamed A. Arafa
}

\begin{abstract}
Background: Amyand's hernia (AH) is defined as protrusion of the vermiform appendix within the sac of the inguinal hernia and usually misdiagnosed as obstructed hernia. It is more common in pediatric patients but there are controversies about dealing with the normally looking appendix in $\mathrm{AH}$. The aim of this study is to present our experience in the management of $\mathrm{AH}$ and highlights the difference in dealing with normally looking appendix between pediatric and adult patients. Patients' demographics, intraoperative, and postoperative outcome were reported and analyzed.

Results: This is a retrospective analysis of 12 pediatric patients aged between 15 days and 5 years presented with $\mathrm{AH}$ and operated in tertiary referral hospital over 10 years. This study included 10 males and 2 females. The median age at the operation was 7 months. Eleven patients were operated using conventional technique, and only one patient was operated using laparoscopy. In 11 patients, the appendix was looking normal and was reduced without appendectomy, and the hernia was repaired. Appendectomy was done in one patient presented with AH containing inflamed appendix. The postoperative course was uneventful in all cases.
\end{abstract}

Conclusions: There is a difference in the management of pediatric and adult patients presenting with $\mathrm{AH}$, and appendectomy is not mandatory in normally looking appendix in pediatric patients.

Keywords: Amyand's hernia, Appendectomy, Children, Management

\section{Background}

Amyand's hernia (AH) is a unique condition due to protrusion of a vermiform appendix in the sac of the inguinal hernia $[1,2]$. It was discovered and firstly described by Claudius Amyand in 1735 when he managed a boy aged 11 years old presented with an inguinal hernia containing inflamed appendix with fistula between thigh and scrotum [3, 4]. The prevalence of Amyand's hernia is less than $1 \%(0.4 \%$ and $0.6 \%)$ according to the literature while the prevalence of acute appendicitis in amyand's hernia reached $0.1 \%[5,6]$. It is three times more common in pediatric patients [7]. It is more common in males, and it has a bimodal age distribution in neonates and geriatric patients above 70 years old $[8,9]$.

Amyand's hernia presents as inguinal or inguinoscrotal swelling, and the preoperative diagnosis is uncommon as it is usually mistaken as incarcerated or strangulated hernia and so, it usually represents a surprise during surgery $[10,11]$. Sonographic diagnosis of appendix within the hernia sac was reported in the

\footnotetext{
* Correspondence: Hishamalmohamady@yahoo.com

General Surgery Department, Faculty of Medicine, Tanta University, Tanta, Egypt
} 
literature [12, 13]. Abominopelvic CT is a useful tool in preoperative diagnosis of Amyand's hernia but this is not a routine investigation in children presented with incarcerated or strangulated hernias [14]. The pathophysiology of Amyand's hernia is still unclear but the acute inflammation of the appendix within the hernia sac may be due to compression by the sharp edge of the internal ring that results in pressure necrosis, bacterial spread, and appendicitis [2, 15]. There are controversies in the literature about dealing with normal looking appendix within the hernia sac when incidentally found during surgery. Many authors recommended repair of the hernia without appendectomy in this condition $[2,8,16]$ but others preferred appendectomy in all patients $[17,18]$.

In this study, we presented our experience in the management of 12 pediatric patients presented with $\mathrm{AH}$ over 10 years at tertiary referral hospital and highlight the difference in dealing with normally looking appendix between pediatric and adult patients.

\section{Methods}

A retrospective analysis of the charts of all patients operated for congenital inguinal hernia presented at Tanta university hospitals and its affiliated hospitals, Egypt, in the period from December 2009 to December 2019. Patient's demographics (age, sex), clinical presentation (history, clinical examination), preoperative investigations (routine investigations and imaging studies), surgical notes, management strategy, and postoperative results were recorded and analyzed.

\section{Results}

The charts of 2500 cases of congenital inguinal hernia were reviewed. AH was found in $12(0.48 \%)$ patients presented by congenital inguinal hernia. Ten patients were boys, and two patients were girls. The median age at the operation was 7 months (range 15 days to 5 years). The clinical presentation was incarcerated inguinal swellings in all patients. Laboratory findings were normal in all patients except one of them who had elevation in the total leucocytic count and CRP found during surgery to be inflamed appendix. Preoperative inguinoscrotal ultrasonography was done in 3 patients only and revealed an incarcerated tubular structure in the hernia sac in 2 patients and incarcerated bowel in one patient which was discovered during surgery to be a cecum and appendix. Emergency surgery was done in all patients. Eleven patients were operated through transverse inguinal incision at the lower abdominal crease, and a normally looking appendix alone was found in the hernia sac in 9 patients which were reduced easily, and herniotomy was done (Fig. 1a-c). The hernia sac was found to contain a sliding cecum with a normal looking appendix in one patient which was reduced with some difficulties, and herniotomy was done (Fig. 2). Inflamed appendix was found in the one patient, and appendectomy was done which facilitates reduction and closure of the hernia sac (Fig. 3). One patient was operated using laparoscopy; the appendix was found normally looking and adherent within the hernia sac; reduction of the appendix was done by external scrotal compression; and the adhesion was dissected using laparoscopic scissor and monopolar diathermy, then the sac was closed using burse string suture at the internal ring (Fig. 4) (Table 1). All patients were discharged at the same day of the operation, and the postoperative course was uneventful in all cases. The patients were followed in the outpatient clinic at 2 weeks, 1 month, and every 3 months. No recurrence was detected in any patient in the follow-up period which extended for 9 months after the operation.

\section{Discussion}

Amyand's hernia is a rare condition and defined as presence of vermiform appendix within inguinal hernia sac. Regarding the pathophysiology of $\mathrm{AH}$, some reports explained that the presence of fibrous connection between the appendix and the testis acts as a guidance to the passage of the appendix with the aid of patent processus vaginalis into inguinal hernia. So, $\mathrm{AH}$ was reported in neonates and premature twins [12, 19-21]. Other reports explained $\mathrm{AH}$ by the repeated microtrauma, adhesions, and recurrent acute inflammation which occurred due to migration of the appendix within the hernia sac $[22,23]$.

Clinically, the preoperative diagnosis of $\mathrm{AH}$ is difficult, and most cases were presented as incarcerated right inguinal or inguinoscrotal swellings so awareness of the surgeon about this rare condition as well as the clinical finding of irreducible hernia without the cardinal symptoms of intestinal obstruction raises the possibility of $\mathrm{AH}$. The general manifestations like fever, vomiting, and abdominal distention depend on the condition of the vermiform appendix whether inflamed or perforated, and the clinical image may be obscured due to the narrow neck of the sac of the herniation which limits the spread of inflammation and peritoneal irrigation [24]. The differential diagnosis of $\mathrm{AH}$ also included torsion of the testis and epididymo-orchitis [25].

Inguionscrotal ultrasonography and CT scan are important tools in predicting this condition [6]. In this study, all patients were presented as right inguinal and inguinoscrotal swellings. Clinical examinations revealed incarceration in all patients without the symptoms and signs of intestinal obstruction. One patient 

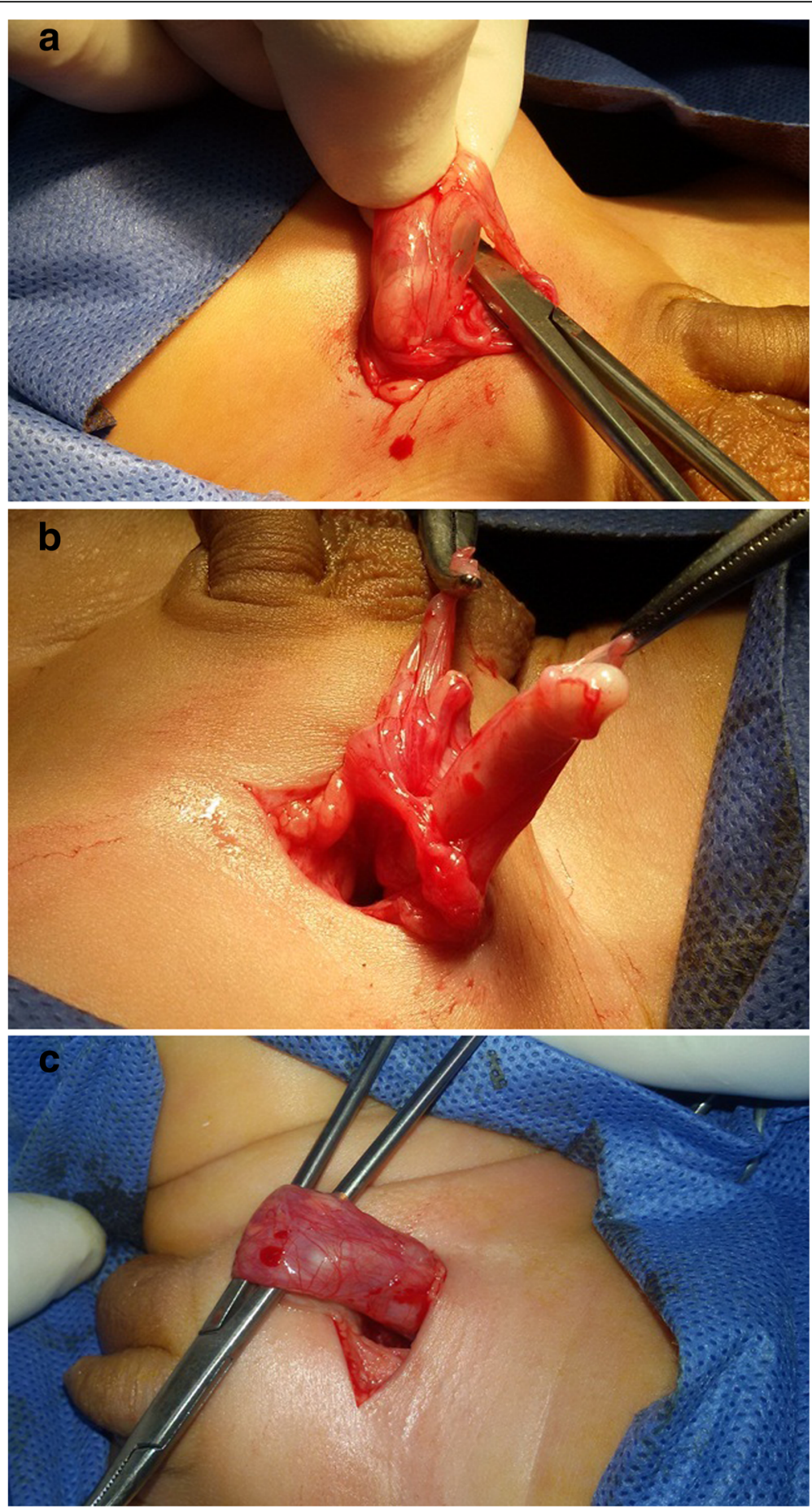

Fig. 1 a-c AH containing normally looking appendix

was suspected clinically to be AH with inflamed appendix because of the general and local manifestation of appendicitis, and the diagnosis was confirmed by laboratory findings and inguinoscrotal ultrasonography. During surgery, acute appendicitis was found, and the appendix was too long and it was descended to the scrotum, and appendectomy was done. Priego et al. reported no cases with acute inflammation of the appendix in their series which include 6 adult patients with AH [17]. Kaymakci et al. had one case of 




Fig. $2 \mathrm{AH}$ containing sliding cecum and appendix

appendicitis in their series which included 30 pediatric patients [26]. Cankorkmaz et al. had 4 cases with acute appendicitis in their series which included 12 pediatric patients [8]. Okur et al. reported also 4 patients with inflamed appendix in their series which included 21 pediatric patients [16]. Milburn and Youngson reported a 10-day-old boy with AH presented with acute hemiscrotum [27]. Livaditi et al. reported two premature neonates with $\mathrm{AH}$, and one of them was found to have perforated appendicitis [28].

Losanoff and Basson described a classification system in 2007 clarifying the operative approach, the methods of dealing with the appendix, and the type of the hernia repair in adults (Table 2) [29], but there is still lacking of consensus about dealing with the normal looking appendix in pediatric patients presented with $\mathrm{AH}$.

In cases of $\mathrm{AH}$ with appendicitis, it is accepted that appendectomy should be performed [26, 30] but the controversies about AH with normal looking appendix is still present. Many authors believed that the normally looking appendix which was incidentally discovered during surgery without any signs of inflammation should not be removed, and prophylactic appendectomy is not necessary [2, 8, 16]. They concluded that, the unnecessary appendectomy may add an operative risk and leads to dissemination of the infection. Also, dissection at the base of the appendix may need extension of the incision and so weakness of the tissues and hence further recurrence; 


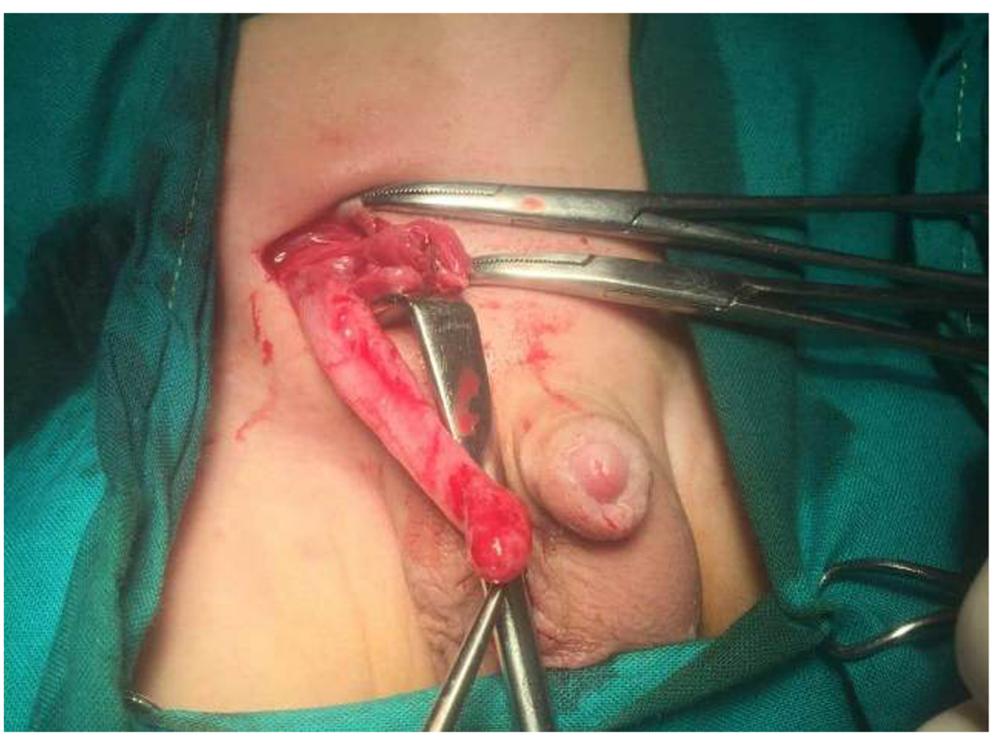

Fig. 3 AH containing inflamed appendix

finally, the appendix may be used in later life in other operations like urinary diversion. We support this opinion in this study as reduction of the normally looking appendix, and repair of the hernia was done in 11 patients, and there were no post-operative complications or recurrences. Other authors choose to make appendectomy to all patients presented with $\mathrm{AH}$. They explained that opinion by the high chance of the appendix to herniate in young patients leading to recurrence may lead to later appendicitis $[17,18]$.
Advances of minimal invasive surgery in the last years made laparoscopic congenital inguinal hernia repair a feasible and simple procedure. It has the advantages of clear visualization of the internal ring in both sides and exploration of the abdomen and pelvis, reduction of the irreducible contents under direct vision and detection of the vascularity of the reduced viscera, precise suturing of the peritoneum at the internal ring, and meticulous manipulation of the vas deference and testicular vessels to avoid injury of

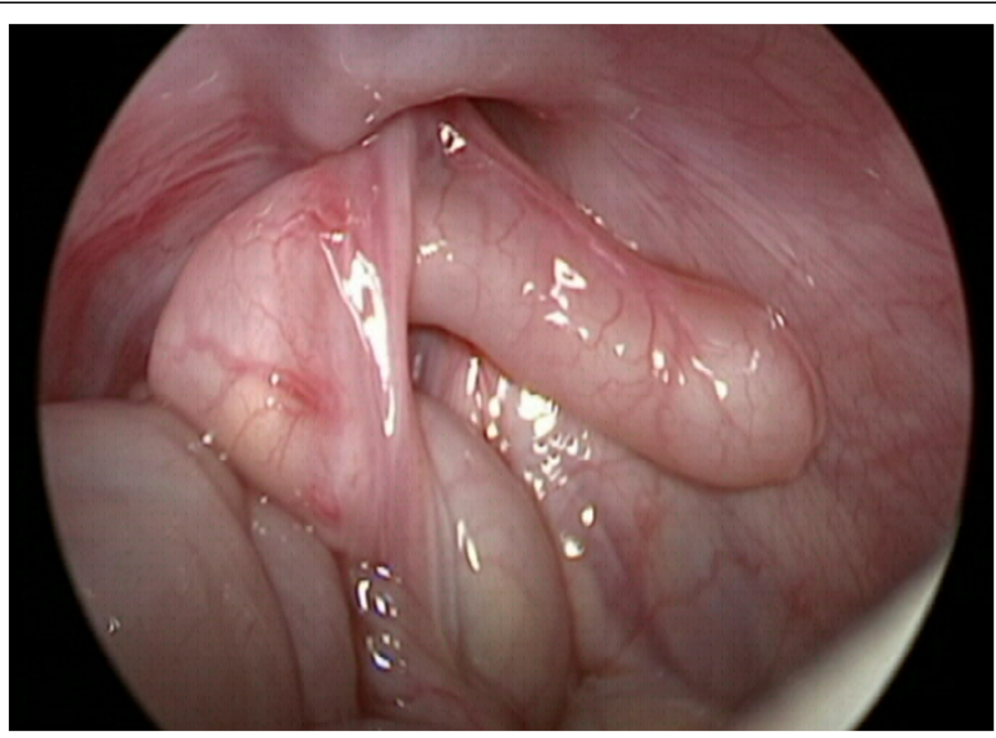

Fig. 4 Laparoscopic view of AH after reduction of the appendix 
Table 1 Patients characteristics

\begin{tabular}{ll}
\hline Patients characteristics & Number \\
\hline Male & 10 \\
Female & 2 \\
Site & \\
1-Unilateral CIH & 9 \\
2-Bilateral CIH & 3 \\
Preoperative ultrasound & 3 \\
1-Incarcerated appendix & 2 \\
2-Incarcerated bowel & 1 \\
Procedure & \\
1-Traditional open approach & 11 \\
2-Laparoscopic approach & 1 \\
Findings & 10 \\
1-Normal looking appendix alone & 1 \\
2-Sliding cecum and normal appendix & 1 \\
3-Inflamed appendix &
\end{tabular}

both structures [31]. Chan et al. reported advantages of the laparoscopic approach over an open approach with regards to postoperative pain, recovery, and wound cosmoses [32]. Tycast et al. reported a 12-year-old boy with $\mathrm{AH}$ who was managed by laparoscopic appendectomy, and the procedure was completed by open repair of inguinal hernia [33]. Rahman et al. reported a 10-week-old boy presented with $\mathrm{AH}$ managed laparoscopically [31]. In this series, there was only one case done laparoscopically where there was adhesion of the appendix within the hernia sac which was easily dissected and reduced under vision aided by external scrotal compression. The appendix was looking normal and so appendectomy was not done.

The main limitations of this study are the small sample size which could be attributed to the rarity of the condition and the study format as a case series with lack of the control group.

Table 2 Losanoff-Basson classification of Amyand's hernia (AH) and their management [28]

\begin{tabular}{|c|c|c|}
\hline $\begin{array}{l}\text { Types } \\
\text { of } \mathrm{AH}\end{array}$ & Features & Surgical management \\
\hline Type 1 & $\begin{array}{l}\text { Normal appendix within } \\
\text { the inguinal hernia }\end{array}$ & $\begin{array}{l}\text { Reduction of appendix or } \\
\text { appendicectomy and mesh } \\
\text { hernioplasty }\end{array}$ \\
\hline Type 2 & $\begin{array}{l}\text { Acute appendicitis with } \\
\text { no abdominal sepsis }\end{array}$ & $\begin{array}{l}\text { Appendicectomy through the } \\
\text { hernia and sutured hernioplasty }\end{array}$ \\
\hline Type 3 & $\begin{array}{l}\text { Acute appendicitis with } \\
\text { abdominal sepsis }\end{array}$ & $\begin{array}{l}\text { Appendicectomy through } \\
\text { laparotomy with sutured } \\
\text { hernioplasty }\end{array}$ \\
\hline Type 4 & $\begin{array}{l}\text { Acute appendicitis associated } \\
\text { with related or unrelated } \\
\text { abdominal pathology }\end{array}$ & $\begin{array}{l}\text { Appendicectomy through } \\
\text { hernia or laparotomy plus } \\
\text { diagnostic workup }\end{array}$ \\
\hline
\end{tabular}

\section{Conclusion}

Amyand's hernia is a rare condition and is always misdiagnosed as strangulated hernia. It should be suspected in cases with long history of incarcerated congenital hernia without clinical manifestation of intestinal obstruction. Careful examination of the appendix must be considered, and routine appendectomy is not mandatory for a normal looking appendix in pediatric patients.

\section{Abbreviations}

$\mathrm{AH}$ : Amyand's hernia

\section{Acknowledgements}

Not applicable.

\section{Authors' contributions \\ HAA gave the idea and collected the patients' data and analyzed them. MAS wrote the paper with revision and the corresponding author. MAM put the study design and followed the patients postoperatively. All authors have read and approved the final version of the manuscript. \\ Funding \\ This study had no funding from any resource.}

\section{Availability of data and materials}

The datasets used and/or analyzed during the current study are available from the corresponding author on reasonable request. Available upon request

\section{Ethics approval and consent to participate}

This study was approved by the Review Board of the Department of General Surgery, Faculty of Medicine, Tanta University, Egypt, on 15 June 2019, but the consent to participate was not applicable as it is a retrospective study. The ethical committee reference number: 2938/12/14.

\section{Consent for publication}

Not applicable as it is a retrospective study.

\section{Competing interests}

All authors have no conflicts of interest or financial ties to disclose. Contents have not published elsewhere, and the paper is not being submitted elsewhere.

Received: 21 January 2020 Accepted: 1 April 2020

Published online: 23 April 2020

\section{References}

1. Thomas WE, Vowles KD, Williamson RC. Appendicitis in external herniae. Ann R Coll Surg Engl. 1982;64(2):121-2.

2. Sharma H, Gupta A, Shekhawat NS, Memon B, Memon MA. Amyand's hernia: a report of 18 consecutive patients over a 15-year period. Hernia. 2007;11(1):31-5.

3. Hutchinson R. Amyand's hernia. J R Soc Med. 1993;86(2):104-5.

4. Logan MT, Nottingham JM. Amyand's hernia: a case report of an incarcerated and perforated appendix within an inguinal hernia and review of the literature. Am Surg. 2001;67(7):628-9.

5. Psarras K, Lalountas M, Baltatzis M, Pavlidis E, Tsitlakidis A, Symeonidis N, et al. Amyand's hernia-a vermiform appendix presenting in an inguinal hernia: a case series. J Med Case Rep. 2011;5:463.

6. Kueper MA, Kirschniak A, Ladurner R, Granderath FA, Konigsrainer A Incarcerated recurrent inguinal hernia with covered and perforated appendicitis and periappendicular abscess: case report and review of the literature. Hernia. 2007;11(2):189-91.

7. Michalinos A, Moris D, Vernadakis S. Amyand's hernia: a review. Am J Surg. 2014;207(6):989-95.

8. Cankorkmaz L, Ozer H, Guney C, Atalar MH, Arslan MS, Koyluoglu G. Amyand's hernia in the children: a single center experience. Surgery. 2010; 147(1):140-3. 
9. Srouji MN, Buck BE. Neonatal appendicitis: ischemic infarction in incarcerated inguinal hernia. J Pediatr Surg. 1978;13(2):177-9.

10. Carey $L C$. Acute appendicitis occurring in hernias: a report of 10 cases. Surgery. 1967;61(2):236-8.

11. Inan I, Myers PO, Hagen ME, Gonzalez M, Morel P. Amyand's hernia: 10 years' experience. Surgeon. 2009;7(4):198-202.

12. Coulier B, Pacary J, Broze B. Sonographic diagnosis of appendicitis within a right inguinal hernia (Amyand's hernia). J Clin Ultrasound. 2006;34(9):454-7.

13. Akfirat M, Kazez A, Serhatlioglu S. Preoperative sonographic diagnosis of sliding appendiceal inguinal hernia. J Clin Ultrasound. 1999;27(3):156-8.

14. Luchs JS, Halpern D, Katz DS. Amyand's hernia: prospective CT diagnosis. J Comput Assist Tomogr. 2000;24(6):884-6.

15. D'Alia C, Lo Schiavo MG, Tonante A, Taranto F, Gagliano E, Bonanno L, et al. Amyand's hernia: case report and review of the literature. Hernia. 2003;7(2): 89-91.

16. Okur MH, Karacay S, Uygun I, Topcu K, Ozturk H. Amyand's hernias in childhood (a report on 21 patients): a single-centre experience. Pediatr Surg Int. 2013;29(6):571-4.

17. Priego P, Lobo E, Moreno I, Sanchez-Picot S, Gil Olarte MA, Alonso N, et al. Acute appendicitis in an incarcerated crural hernia: analysis of our experience. Rev Esp Enferm Dig. 2005;97(10):707-15.

18. Gurer A, Ozdogan M, Ozlem N, Yildirim A, Kulacoglu H, Aydin R. Uncommon content in groin hernia sac. Hernia. 2006;10(2):152-5.

19. Oguzkurt P, Kayaselcuk F, Oz S, Arda IS, Oguzkurt L. Sliding appendiceal inguinal hernia with a congenital fibrovascular band connecting the appendix vermiformis to the right testis. Hernia. 2001;5(3):156-7.

20. Martins JL, Peterlini FL, Martins EC. Neonatal acute appendicitis: a strangulated appendix in an incarcerated inguinal hernia. Pediatr Surg Int. 2001;17(8):644-5

21. Baldassarre E, Centonze A, Mazzei A, Rubino R. Amyand's hernia in premature twins. Hernia. 2009;13(2):229-30.

22. Abu-Dalu J, Urca I. Incarcerated inguinal hernia with a perforated appendix and periappendicular abscess: report of a case. Dis Colon Rectum. 1972; 15(6):464-5.

23. Weber RVHZ, Kral JG. Amyand's hernia: etiologic and therapeutic implications of two complications. Surg Rounds. 1999;22:552-6.

24. Lyass S, Kim A, Bauer J. Perforated appendicitis within an inguinal hernia: case report and review of the literature. Am J Gastroenterol. 1997;92(4):700-2.

25. Yazici M, Etensel B, Gursoy H, Ozkisacik S, Erkus M, Aydin ON. Infantile Amyand's hernia. Pediatr Int. 2003;45(5):595-6.

26. Kaymakci A, Akillioglu I, Akkoyun I, Guven S, Ozdemir A, Gulen S. Amyand's hernia: a series of 30 cases in children. Hernia. 2009;13(6):609-12.

27. Milburn JA, Youngson GG. Amyand's hernia presenting as neonatal testicular ischaemia. Pediatr Surg Int. 2006;22(4):390-2.

28. Livaditi E, Mavridis G, Christopoulos-Geroulanos G. Amyand's hernia in premature neonates: report of two cases. Hernia. 2007:11(6):547-9.

29. Losanoff JE, Basson MD. Amyand hernia: what lies beneath--a proposed classification scheme to determine management. Am Surg. 2007;73(12): 1288-90.

30. Thomasset SC, Villatoro E, Wood S, Martin A, Finlay K, Patterson JE. An unusual Spigelian hernia involving the appendix: a case report. Cases J. 2010;3:22.

31. Rehman MR, Panteli C, Tsang T. Laparoscopic repair of Amyand's hernia in an 8-week-old infant. Hernia. 2010;14(4):443-5.

32. Chan KLHW, Tam PK. Prospective randomized single-center, single-blind comparison of laparoscopic vs open repair of pediatric inguinal hernia. Surg Endosc. 2005;19:927-32.

33. Tycast JF, Kumpf AL, Schwartz TL, Coln CE. Amyand's hernia: a case report describing laparoscopic repair in a pediatric patient. J Pediatr Surg. 2008; 43(11):2112-4.

\section{Publisher's Note}

Springer Nature remains neutral with regard to jurisdictional claims in published maps and institutional affiliations.

\section{Submit your manuscript to a SpringerOpen ${ }^{\circ}$ journal and benefit from:}

- Convenient online submission

- Rigorous peer review

- Open access: articles freely available online

- High visibility within the field

- Retaining the copyright to your article

Submit your next manuscript at $\boldsymbol{\nabla}$ springeropen.com 